\title{
Influence of physico-chemical properties of porous microcarriers on the adhesion of an anaerobic consortium
}

\author{
MA Pereira, MM Alves, J Azeredo, M Mota and R Oliveira \\ Centro de Engenharia Biológica-IBQF, Universidade do Minho, 4700 Braga, Portugal
}

\begin{abstract}
The ability for biomass colonization of four porous mineral microcarriers (sepiolite, clay, pozzolana and foam glassPoraver ${ }^{\mathrm{TM}}$ ), was studied and related to their surface properties. The surface hydrophobicity of the mineral carriers was a more important factor influencing colonization by the anaerobic consortium than was surface charge. It was possible to correlate linearly the degree of hydrophobicity with the biomass retention capacity. Although the thermodynamic theory did not explain adhesion, an increase in cell attachment was directly related to the decrease of the positive values of the free energy of adhesion. Surface roughness, porosity and the amount of surface $\mathbf{M g}^{2+}$, were also determinant factors in bacterial immobilization. However a great biomass accumulation can originate a decrease in biological activity due to mass transfer limitations. Journal of Industrial Microbiology \& Biotechnology (2000) 24, $181-186$.
\end{abstract}

Keywords: biomass-support interactions; microcarriers; surface properties; methanogenic activity

\section{Introduction}

In the last two decades anaerobic digestion technology significantly improved due, in large part, to better biomass immobilization technology. Therefore, knowledge of the basic processes of biomass immobilization is important.

Microorganisms present in biofilms or microbial aggregates are more protected from adverse environmental conditions [9,16]. Although biomass immobilization in the popular Upflow Anaerobic Sludge Blanket (UASB) reactor is based on self-granulation, anaerobic filters (AF) and fluidized bed (FB) digesters are examples of true biofilm reactors. In FB digesters, sludge retention is primarily governed by adhesion and growth on a moving surface and the performance of this kind of digester was reported to be highly dependent on the characteristics of the support material used for biomass colonization [12].

The colonization of solid surfaces is ruled by the surface properties of both interacting bodies (surface charge, surface tension, wettability, composition, porosity and roughness). Surface charge and surface tension are responsible for short and long range interactions. Long range interactions have been described by DLVO (after Derjaguin, Landau, Verwey and Overbeek) theory which postulates that the net force of interaction between cells and the adhesion substratum arises from the balance between van der Waals forces of attraction and electrostatic forces of repulsion [19]. Short-range interactions take place when the cells are close to the surface $(<2 \mathrm{~nm})$ and include Born repulsion forces, hydration forces and hydrophobic and steric interactions [10]. When a bacterium and a surface enter into direct contact, the water film present between the interacting entities has to be removed. This is in accordance with the thermodynamic theory of adhesion and is

Correspondence: Dr R Oliveira, Dept Engenharia Biológica, Universidade do Minho, 4709 Braga Codex, Portugal. E-mail: roliveira@deb.uminho.pt Received 9 August 1999; accepted 1 December 1999 expressed by the Dupré equation [1] which states that the Gibbs free energy of interaction can be calculated assuming that the interfaces between bacteria/liquid medium and solid/liquid medium are replaced by a bacteria/solid interface. Hydrophobicity has been considered the most important short-range interaction force in bacterial attachment $[8,30]$. A number of authors reported that the hydrophobicity of the adhesion surface plays a determinant role in bacterial adhesion, being even more important than the surface charge $[3,11,23,24,26]$. It should be stressed that surface charge is usually assessed in terms of zeta potential. As they are directly related, both are used interchangeably throughout the literature to express qualitatively the electrical surface properties of colloidal particles.

Apart from these properties, surface morphology is also important. Adhesion is enhanced on porous surfaces on account of a higher surface area for bacteria attachment. However, pore size is an important feature for surface colonization [17]. Accordingly, the best pore size for attachment should range between the smallest cell dimension and five times its largest dimension. Shimp and Pfaender [22] also reported that microbe-size crevices favor surface colonization.

Some authors claim that surface roughness is more important for colonization than internal surface area [20]. Scanning electron microscopy revealed that the initial colonization starts from surface irregularities such as cracks, grooves or abrasion defects. Moreover, on a rough surface, microorganisms are more protected against shear forces [21].

Many authors reported an enhancement of adhesion in the presence of specific surface groups, such as $\mathrm{Ca}^{2+}$ and $\mathrm{Mg}^{2+}[5,26,28]$ due to cation bridges between the negatively charged bacterial surface and the substratum [19].

The aim of this work was to study the surface properties of four porous carriers (clay, foam glass, pozzolana and sepiolite) and relate these properties with the biomass retention capacity, taking into account methanogenic activity. 
Table 1 Characteristics of the microcarriers

\begin{tabular}{lcccc}
\hline Material & Diameter $(\mathrm{mm})$ & Dry grain density $\left(\mathrm{g} \mathrm{cm}^{-3}\right)$ & Wet grain density $\left(\mathrm{g} \mathrm{cm}^{-3}\right)$ & $\begin{array}{c}\text { Internal porous } \\
\left(\mathrm{cm}^{3} \mathrm{~cm}_{\text {particle }}{ }^{-3}\right)\end{array}$ \\
\hline Clay & $3.35-4.75$ & $0.714 \pm 0.017$ & $1.094 \pm 0.001$ & $0.381 \pm 0.019$ \\
Foam glass & $3.35-4.75$ & $0.307 \pm 0.012$ & $1.101 \pm 0.013$ & $0.796 \pm 0.016$ \\
Pozzolana & $3.35-4.75$ & $1.532 \pm 0.068$ & $2.039 \pm 0.049$ & $0.508 \pm 0.100$ \\
Sepiolite & $3.35-4.75$ & $0.991 \pm 0.066$ & $1.627 \pm 0.049$ & $0.638 \pm 0.114$ \\
\hline
\end{tabular}

${ }^{\mathrm{a}}$ Water accessible.

\section{Materials and methods}

\section{Microcarriers and biomass retention capacity}

Four porous microcarriers were tested: sepiolite, foam glass (Poraver $^{\mathrm{TM}}$, Dennert, Poraver GmbH, Germany), clay and pozzolana. Table 1 summarizes some of their relevant characteristics. The dry grain density was measured by mercury picnometry. The wet grain density was determined by water picnometry, after forcing the penetration of water inside the pores of each material (autoclaving). water accessible porosity was considered to be a more suitable parameter than total porosity to characterize the susceptibility of each material for internal microbial colonization.

The biomass retention capacity, expressed as volatile solids (VS) per volume of particle, of each microcarrier was determined in a previous work [2]. Each material (heated at $550^{\circ} \mathrm{C}$ and autoclaved) was placed in a continuous reactor, under similar environmental conditions. At the end of the adhesion experiment the specific methanogenic activity of the adhered biomass was determined by measuring the initial rate of degradation of a stock solution of volatile fatty acids (VFA) in batch assays, as detailed elsewhere [2].

\section{Surface tension}

The surface tension of the anaerobic consortium was calculated according to the approach of van Oss et al [32], using the values of the contact angles formed by water, formamide and di-iodomethane on bacterial lawns [6]. The surface tension of the carriers, due to their shape, was assessed by means of the thin layer wicking technique as described by Teixeira et al [27].

\section{Zeta potential}

The zeta potential of the mineral carriers was determined (after grinding) by measuring the electrophoretic mobility in a Zeta-Meter 3.0+ (Zeta-Meter Inc, USA) at $100 \mathrm{~V}$. Determinations were performed in the culture medium adjusted to $\mathrm{pH}$ values in the range between 6.7 and 7.7 with $\mathrm{NaOH}$ and $\mathrm{HCl}$. The same procedure was followed to obtain the zeta potential of the cells. However, in this case anaerobic conditions were maintained inside the electrophoretic cell by saturating the culture medium with nitrogen.

\section{Surface morphology and chemical composition}

The surface morphology of each material was evaluated by scanning electron microscopy (Leica, Cambridge S360) [2]. Prior to microscopic examination, samples were sputtercoated with gold. The chemical composition of each
Table 2 Attached biomass ( \pm 95\% confidence interval)

\begin{tabular}{lc}
\hline Material & $\begin{array}{c}\text { Attached biomass } \\
\left(\mathrm{g} \mathrm{VS} \mathrm{L}_{\text {particle }}^{-1}\right)^{\mathrm{a}}\end{array}$ \\
\hline Sepiolite & $24.5 \pm 1.5$ \\
Foam glass & $15.4 \pm 1.2$ \\
Clay & $14.9 \pm 0.5$ \\
Pozzolana & $13.3 \pm 0.4$
\end{tabular}

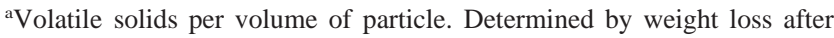
heating at $550^{\circ} \mathrm{C}$.

material was determined by EDS (Energy Dispersion Spectroscopy) (Leica, Cambridge S360).

\section{Results and discussion}

\section{Biomass colonization}

The four assayed carriers exhibited different susceptibilities to bacterial colonization. Sepiolite was the most colonized material followed by foam glass, clay and pozzolana (Table 2).

In a previous work describing the adhesion experiment, the amount of volatile solids (VS) attached was expressed per internal porous volume [2]. This representation allowed differentiation and qualification of the internal porosity relative to the biomass retention capacity, which was related to surface morphology, particularly to pore size. Table 3 summarizes these results.

The rough surface of sepiolite with cell-size crevices favored adhesion. On the other hand the relative smooth surface and large pores of foam glass accumulated less biomass.

The conclusion that sepiolite is an efficient microcarrier for biomass immobilization is in accordance with earlier works. Huysman et al [14] observed that sepiolite was the

Table 3 Characteristics of the microcarriers and attached biomass, expressed per internal porous volume $( \pm 95 \%$ confidence interval)

\begin{tabular}{lccc}
\hline Material & Roughness & $\begin{array}{c}\text { Surface } \\
\text { appearance/pore } \\
\text { size }\end{array}$ & $\begin{array}{c}\text { Attached biomass } \\
\text { g VS L }_{\text {internal porous volume }}{ }^{-1}\end{array}$ \\
\hline Sepiolite & +++ & cell size crevices & $38.4 \pm 2.4$ \\
Clay & +++ & $10-100 \mu \mathrm{m}$ & $35.1 \pm 1.0$ \\
Pozzolana & ++ & $10-300 \mu \mathrm{m}$ & $29.3 \pm 1.3$ \\
Foam glass & + & $20-1000 \mu \mathrm{m}$ & $19.3 \pm 1.4$ \\
\hline
\end{tabular}




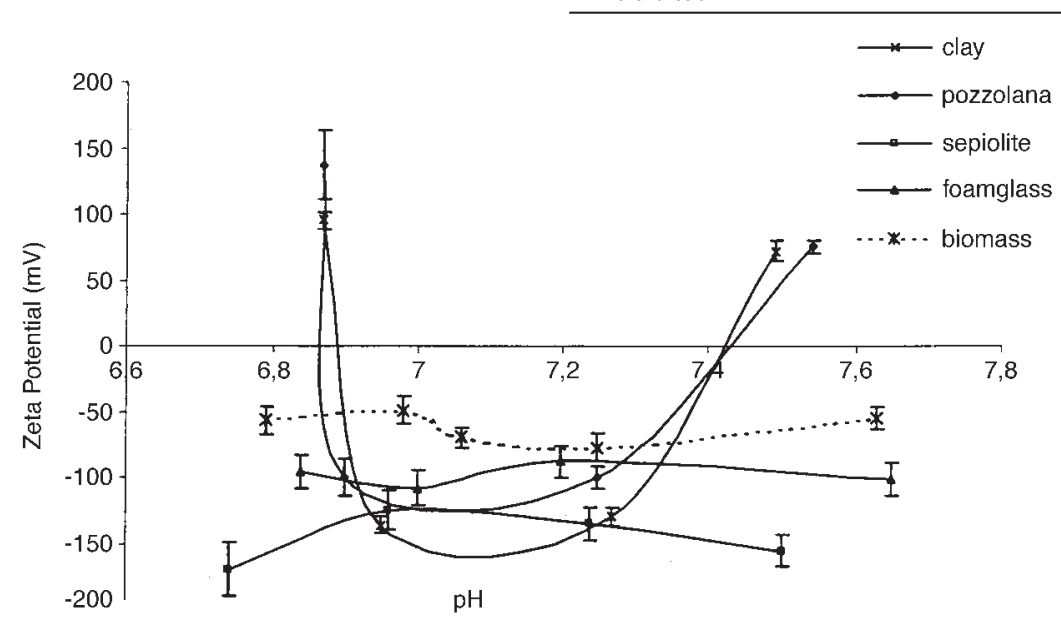

Figure 1 Zeta-potential values of the anaerobic consortium and microcarriers in the operating $\mathrm{pH}$ range.

most efficient material for microbial colonization, when compared with glass beads, argex, activated carbon and a zeolite. The amount of macro and micropores and the surface roughness of sepiolite were suggested to be important factors for its ability to achieve a good and fast microbial colonization $[18,22]$.

In the present work an attempt to explain the different degrees of colonization was made by investigating some surface properties such as surface tension, hydrophobicity and chemical composition of the four materials.

\section{Surface charge}

The surface charge of the interacting entities (cells and carriers) was evaluated by means of zeta potential (Figure 1). Both pozzolana and clay behaved similarly showing an oscillatory pattern of zeta potential with $\mathrm{pH}$ : negative for $\mathrm{pH}$ between 6.9 and 7.5 and positive outside this $\mathrm{pH}$ range. In the $\mathrm{pH}$ range $6.9-7.5$, where all the materials show a negative zeta potential, foam glass is less negatively charged. Bacteria also present a negative zeta potential for $\mathrm{pH}$ values between 6.9 and 7.5. Therefore, in this $\mathrm{pH}$ range a high electrostatic repulsion would prevent bacteria from adhering to the carriers. Moreover, it was not possible to find any direct correlation between a less negative surface charge and a higher tendency for adhesion. Thus, in the present situation, this parameter has a minor influence on bacterial adhesion.

\section{Surface tension}

According to van Oss et al [32], the surface tension of a substance comprises a component arising from Lifshitz-van der Waals interactions $\left(\gamma^{\mathrm{LW}}\right)$ and a component related to polar interactions $\left(\gamma^{\mathrm{AB}}\right)$ of the electron acceptor-electron donor type, $\gamma^{+}$and $\gamma^{-}$, respectively $\left(\gamma^{\mathrm{AB}}=2\left[\gamma^{+} \gamma^{-}\right]^{1 / 2}\right)$.

From the data presented in Table 4 it is clear that all the surfaces are predominantly electron donor $\left(\gamma^{-} \gg \gamma^{+}\right)$. The electron acceptor parameter of all the surfaces studied is very small; therefore the apolar component has a greater contribution for the overall surface tension than the polar component. Knowing surface tension values it was possible to calculate the free energy of adhesion [1].

Thermodynamically, adhesion is favored when it leads to a decrease of the free energy $(\Delta G)$ at the interface bacteria
Table 4 Surface tension and surface tension components of the mineral carriers and the bacterial cells (values in $\mathrm{mJ} \mathrm{m}^{-2}$ at $20^{\circ} \mathrm{C}$ )

\begin{tabular}{lrrrrr}
\hline Surface & $\gamma^{\mathrm{LW}}$ & $\gamma^{+}$ & $\gamma^{-}$ & $\gamma^{\mathrm{AB}}$ & $\gamma^{\text {tot }}$ \\
\hline Cells & 29.6 & 3.5 & 55.9 & 27.9 & 57.5 \\
Clay & 50.7 & 0.8 & 52.0 & 12.9 & 63.6 \\
Sepiolite & 42.1 & 0.7 & 37.0 & 10.2 & 52.3 \\
Pozzolana & 49.3 & 3.4 & 62.6 & 29.2 & 78.5 \\
Foam glass & 52.9 & 0.1 & 80.4 & 5.7 & 58.6 \\
\hline
\end{tabular}

$\gamma^{\mathrm{LW}}=$ apolar component of surface tension; $\gamma^{+}=$electron acceptor parameter of the polar component of surface tension; $\gamma^{-}=$electron donor parameter of the polar component of surface tension; $\gamma^{\mathrm{AB}}=$ polar component of surface tension; $\gamma^{\text {tot }}=$ total surface tension.

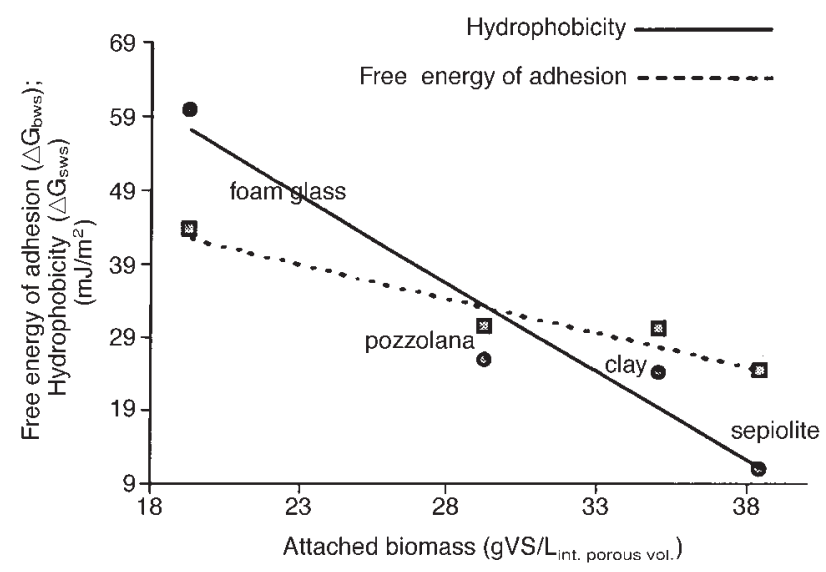

Figure 2 Interfacial free energy of adhesion $\left(\Delta \mathrm{G}_{\mathrm{bws}}\right)$ and hydrophobicity $\left(\Delta \mathrm{G}_{\mathrm{sws}}\right)$ of the carriers $v s$ attached biomass expressed as volatile solids per litre of internal porous volume.

(b)/water (w)/substratum (s), meaning a negative value of $\Delta \mathrm{G}_{\text {bws }}$. In this case, theoretically, the anaerobic biomass would not adhere to the assayed carriers because the free energy of adhesion is always positive (Figure 2). This anomaly reveals limitations in thermodynamic theory, which has also been reported by other authors [7]. Nevertheless a decrease in the interfacial free energy seems to correlate 

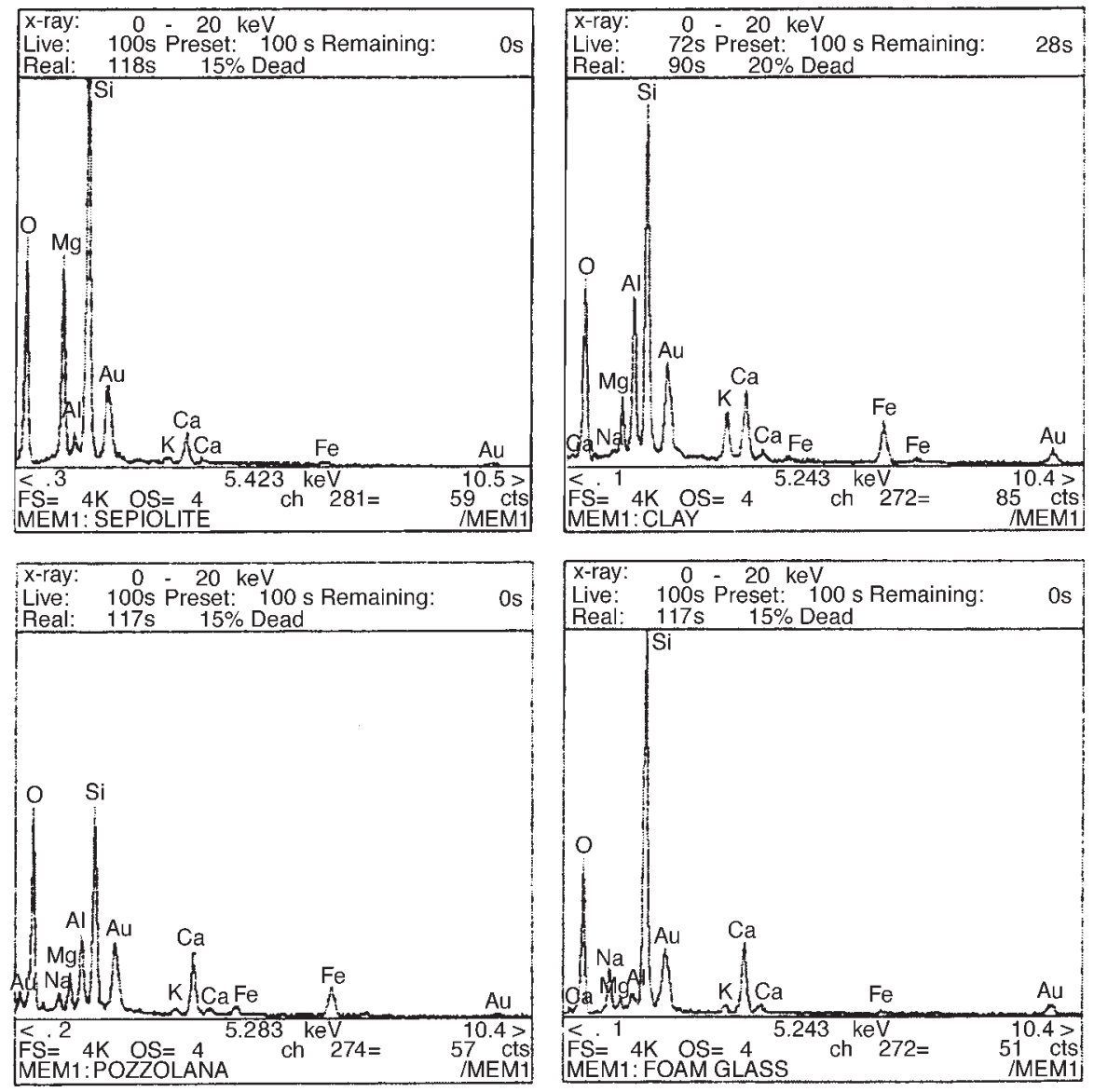

Figure 3 Elemental surface composition of foam glass, sepiolite, pozzolana, and clay obtained by energy dispersion spectroscopy (EDS) analysis.

with the biomass retention capacity of each material (Figure 2). In fact, the material that had the highest biomass retention capacity, sepiolite, showed a less positive free energy of interaction with the cells, followed by clay, pozzolana and foam glass. Other authors reported a similar behavior for different types of microorganisms and surfaces $[7,25]$. This means that for each bacterial strain a decrease in the free energy of adhesion is indicative of an increase in the number of adhering cells.

\section{Surface hydrophobicity}

According to the definition of hydrophobicity proposed by van Oss and Giese [31], a solid is considered hydrophobic when the free energy of interaction between its surface molecules in the presence of water $\left(\Delta \mathrm{G}_{\mathrm{sws}}\right)$ is negative; otherwise it will be hydrophilic. It should be pointed out that based on this concept the absolute degree of hydrophobicity or hydrophilicity can be precisely expressed in applicable SI units, which also makes possible the use of mathematical correlations.

With the data presented in Table 4 it was possible to calculate $\Delta \mathrm{G}_{\mathrm{sws}}[4,31]$. As all the materials have a $\Delta \mathrm{G}_{\text {sws }}>0$, it can be said that they are all hydrophilic.

Foam glass was the most hydrophilic support assayed (Figure 2), mainly due to its greater electron donor ability (Table 4). The other carriers were less hydrophilic than foam glass, having a lower electron donancy. As cells are also very hydrophilic $\left(\Delta \mathrm{G}_{\mathrm{sws}}=29.8 \mathrm{~mJ} \mathrm{~m}^{-2}\right)$, the interactions took place between two hydrophilic entities. Some authors $[8,29]$ claim that adhesion is favored between hydrophobic surfaces because a closer contact is attained when the water layer between the two interacting entities is removed, which is also facilitated if at least one of the surfaces is hydrophobic. Although all the surfaces assayed were hydrophilic it was found that a decrease in surface hydrophilicity leads to an increase in cell attachment (Figure 2).

\section{Surface composition}

The presence of divalent cations has also been considered important in the adhesion process [26]. Divalent cations such as $\mathrm{Ca}^{2+}$ and $\mathrm{Mg}^{2+}$ may provide the existence of punctual positive charges on the material surface that can promote the establishment of ionic bridges, resulting in an attractive interaction. From the EDS analysis (Figure 3), it can be seen that a significant amount of $\mathrm{Mg}^{2+}$ was found in sepiolite, the microcarrier that exhibited the highest biomass retention capacity.

\section{Methanogenic activity}

A good carrier for biomass colonization should not only promote high cell retention but also high biomass activity. Clay and pozzolana supported the highest specific biological activity and had an intermediate level of colonization, 
Table 5 Specific methanogenic activity (SMA) of the attached biomass and volumetric methanogenic activity (VMA) of the colonised microcarriers \pm $\pm 95 \%$ confidence interval $)$

\begin{tabular}{lcc}
\hline $\begin{array}{l}\text { Biomass } \\
\text { attached to }\end{array}$ & $\begin{array}{l}\mathrm{SMA}^{\mathrm{a}}(\mathrm{g} \text { VFA-COD } \\
\left.\mathrm{g} \mathrm{VS}_{\text {attached }}{ }^{-1} \text { day }^{-1}\right)^{\mathrm{b}}\end{array}$ & $\begin{array}{c}\text { VMA (g VFA-COD } \\
\left.\mathrm{L}_{\text {colonized particle }}^{-1} \text { day }^{-1}\right)^{\mathrm{c}}\end{array}$ \\
\hline Clay & $0.329 \pm 0.003$ & $4.4 \pm 0.4$ \\
Foam glass & $0.289 \pm 0.010$ & $4.4 \pm 1.2$ \\
Pozzolana & $0.340 \pm 0.038$ & $5.1 \pm 0.5$ \\
Sepiolite & $0.173 \pm 0.007$ & $4.2 \pm 1.5$ \\
Non-attached & $0.348 \pm 0.022$ & - \\
\hline
\end{tabular}

${ }^{a}$ The methanogenic activity of the attached biomass was determined by measuring the initial rate of volatile fatty acids (VFA) degradation in strict anaerobic batch assays. A volume of $0.26 \mathrm{ml}$ of a VFA solution of acetate, propionate and butyrate with a chemical oxygen demand (COD) ratio 24:34:41 was added to the biomass to make up a working volume of $50 \mathrm{ml}$ with an initial COD of $2.65 \mathrm{~g} \mathrm{~L}^{-1}$ in each vial.

${ }^{b}$ VFA consumption expressed as COD loss per gram of volatile solids attached to each carrier per day.

${ }^{c}$ VFA consumption expressed as chemical COD per litre of colonized particle per day.

whereas the great amount of biomass that colonized sepiolite had a low specific methanogenic activity $(50 \%$ of the non-attached biomass, Table 5). Differences in the methanogenic activity of the colonized microcarriers were only marginal (Table 5, last column).

The balanced effect observed between the specific methanogenic activity (SMA) and the attached biomass suggests a loss of activity of the biomass immobilized in the highest colonized carriers, probably due to diffusion limitations [2]. On the other hand, the accumulation of inert organic matter, ie extracellular polymers, may indirectly affect the specific activity, overestimating the biomass measured as volatile solids. A similar result was obtained by Garcia-Calderón et al [13] who found a similar overall performance for three fluidized bed reactors operating with different microcarriers, in spite of the differences in the attached biomass. Kuba et al [15] also reported the existence of an estimated active biomass concentration smaller than the measured attached volatile solids due to accumulation of inert organic matter.

For practical purposes, the importance of the microcarrier characteristics seems to be more relevant for the startup process, which is greatly influenced by the adhesion kinetics. A surface, such as sepiolite will assure a fast adhesion and consequently the start-up time will be reduced. During steady-state operation, manipulation of operating conditions can control unwanted excessive biofilm growth.

\section{Conclusions}

The results of this study show that the surface hydrophobicity of the mineral carriers is more important for colonization by the anaerobic consortium than the surface charge. In fact, the biomass retention capacity correlates linearly with the degree of surface hydrophobicity. The thermodynamic theory was not suitable to explain the attachment of the biomass. However, a direct relation was found between a decrease in positive free energy of interaction and an increase in cell retention capacity. Adhesion occurred preferentially in rough surfaces. Porosity was also a very important surface characteristic, adhesion being enhanced in the carriers with smaller pore size.

From the colonization point of view the best carrier was sepiolite which presented the lowest value of free energy of adhesion, the greatest hydrophobicity, the highest roughness, and the presence of a higher amount of $\mathrm{Mg}^{2+}$ at the surface. However, it is also important to take into account the effect of mass transfer limitations due to a great biomass accumulation, which can decrease the biological activity of a well-colonized carrier. In practice this problem can be overcome by manipulating operating conditions such as upflow velocity.

\section{References}

1 Absolom DR, FV Lamberti, Z Policova, W Zing, CJ van Oss and AW Neumann. 1983. Surface thermodynamics of bacterial adhesion. Appl Environ Microbiol 46: 90-97.

2 Alves MM, MA Pereira, F Polanco, JM Novais and M Mota. 1998. A new device to select microcarriers for biomass immobilization: application to an anaerobic consortium. Wat Environ Res 71: 209-217.

3 Azeredo J and R Oliveira. 1999. Exopolymers in bacterial adhesion: interpretation in terms of DLVO and XDLVO theories. Coll Surf B: Biont 14: 141-148.

4 Azeredo J, I Ramos, L Rodrigues, R Oliveira and J Teixeira. 1997. Yeast flocculation: a new method for characterizing cell surface interactions. J Institute Brewing 103: 359-361.

5 Bellon-Fontaine MN, N Mozes, HC van der Mei, J Sjollema, O Cerf, PG Rouxhet and HJ Busscher. 1990. A comparison of thermodynamic approaches to predict the adhesion of dairy microorganisms to solid substrata. Cell Biophys 17: 93-106.

6 Busscher HJ, AH Weerkamp, HC van der Mei, AW van Pelt, HP De Jong and J Arends. 1984. Measurement of the surface free energy of bacterial cell surfaces and its relevance for adhesion. Appl Environ Microbiol 48: 980-983.

7 Busscher HJ and AH Weerkamp. 1987. Specific and non-specific interactions in bacterial adhesion to solid substrata. FEMS Microbiol 46: 165-173.

8 Busscher HJ, J Sjollema and HC van der Mei. 1990. Relative importance of surface free energy as a measure of hydrophobicity in bacterial adhesion to surfaces. In: Microbial Cell Surface Hydrophobicity (Doyle RJ and Rosenberg M, eds), pp 335-360, American Society of Microbiology, Washington.

9 Costerton JW. 1987. Bacterial biofilms in nature and disease. Ann Rev Microbiol 41: 453-464.

10 Elimelech M, J Gregory, X Jia and R William. 1995. Particle deposition and aggregation-measurements, modelling and simulation. Colloid and Surface Engineering Series, Butterworth-Heinemann, Oxford.

11 Fletcher M and GI Loeb. 1979. Influence of substratum characteristics on the attachment of marine Pseudomonas to solid surfaces. Appl Environ Microbiol 37: 62-72.

12 Fox P, MT Suidan and JT Bandy. 1990. A comparison of media types in acetate fed expanded-bed anaerobic reactors. Wat Res 24: 827-835.

13 Garcia-Calderón D, P Buffière, R Moletta and S Elmaleh. 1996. Comparison of three granular support materials for anaerobic fluidized bed systems. Biotechnol Lett 18: 731-736.

14 Huysman P, P Van Meenen, P Van Assche and W Verstraete. 1983. Factors affecting colonization of non porous and porous packing materials in model upflow methane reactors. Biotechnol Lett 5: 643-648.

15 Kuba T, H Furumai and T Kusuda. 1990. A kinetic study on methanogenesis of attached biomass in a fluidized bed. Wat Res 24: 13651372

16 Lazarova V and J Manem. 1995. Biofilm characterization and activity analysis in water and wastewater treatment. Wat Res 29: 2227-2245.

17 Messing RA and RA Oppermann. 1979. Pore dimensions for accumulating biomass. I. Microbes that reproduce by fission or by budding. Biotechnol Bioeng 21: 49-58.

18 Muñoz MA, JM Sanchez, JM Rodriguez-Maroto, MA Moriñigo and JJ Borrego. 1994. Evaluation of the use of sepiolite of optimize the 
methanogenesis from anaerobic domestic sludges in laboratory conditions. Wat Res 28: 195-200.

19 Oliveira R. 1997. Understanding adhesion: a means to prevent fouling. Experimental Thermal and Fluid Science 14: 316-322.

20 Petrozzi S, IJ Dunn, E Heinzle and OM Kut. 1991. Carrier influence in anaerobic biofilm fluidized beds for treating vapor condensate from the sulfite cellulose process. Can J Chem Eng 69: 527-553.

21 Quirynen MB and CM Bollen. 1995. The influence of surface roughness and surface-free energy on supra and subgingival plaque formation in man. J Clin Periodontol 22: 1-14.

22 Shimp RJ and FK Pfaender. 1982. Effect of surface area and flow rate on marine bacterial growth in activated carbon columns. Appl Environ Microbiol 44: 471-477.

23 Sousa M, J Azeredo, J Feijó and R Oliveira. 1997 Polymeric supports for the adhesion of autotrophic nitrifying bacteria. Biotechnol Techn 11: 755-758.

24 Stenstrom TA. 1989. Bacterial hydrophobicity, an overall parameter for the measurement of adhesion potential to solid particles. Appl Environ Microbiol 55: 142-147.

25 Teixeira P and R Oliveira. 1998. The importance of surface properties in the selection of supports for nitrification in airlift bioreactors. Bioproc Engin 19: 143-147.
26 Teixeira P and R Oliveira. 1999. Influence of surface characteristics on the adhesion of Alcaligenes denitrificans to polymeric substrates. J Adhesion Sci Technol 13: 1243-1362.

27 Teixeira P, J Azeredo, R Oliveira and E Chibowski. 1998. Interfacial interactions between nitrifying bacteria and mineral carriers in aqueous media determined by contact angle measurements and thin layer wicking. Coll Surf B: Bioint 12: 69-75.

28 Van Hoogmoed CG, HC van der Mei and HJ Busscher. 1997. The influence of calcium on the initial adhesion of S. thermophilus to stainless steel under flow studied by mettalurgical microscopy. Biofouling 11: $167-176$

29 van Loosdrecht M, W Norde, L Lyklema and J Zehnder. 1990. Hydrophobic and electrostatic parameters in bacterial adhesion. Aquatic Sci 51: $103-114$.

30 Van Oss CJ. 1997. Hydrophobicity and hydrophilicity of biosurfactants. Curr Opinion Coll Int Sci 2: 503-512.

31 Van Oss CJ and RF Giese. 1995. The hydrophilicity and hydrophobicity of clay minerals. Clay Minerals 43: 474-477.

32 Van Oss CJ, MK Chaudhury and RJ Good. 1987. Monopolar surfaces. Adv Coll Int Sci 28: 35-64. 